\title{
CRISE DOS SERVIÇOS DE SAÚDE NO COTIDIANO DA MÍDIA IMPRESSA
}

\author{
Vera Sonia Mincoff Menegon \\ Universidade Católica Dom Bosco, Campo Grande, Brasil
}

\begin{abstract}
RESUMO: Apoiando-nos na perspectiva da Psicologia Social, acatamos o pressuposto de que a mídia é um importante espaço de difusão de informações, atuando como co-produtora de sentidos e de subjetividades no cotidiano das pessoas. Assim, a partir da análise de notícias, publicadas em jornais de Campo Grande, MS, tendo como tema serviços de saúde e, mais especificamente, notícias sobre um período de crise nesses serviços, problematizamos o posicionamento do hospital como lócus privilegiado no cuidado com a saúde e as formas verticais de negociação. A ruptura com essa associação e a abertura ao diálogo é um grande desafio para que o Sistema Único de Saúde (SUS) se constitua em um sistema público, pautado pelos eixos da integralidade e da humanização na atenção à saúde que, no debate atual, formatam propostas defendidas pela Saúde Coletiva e outras áreas que atuam na saúde, entre eles a Psicologia.
\end{abstract}

PALAVRAS-CHAVE: Psicologia Social; saúde pública; mídia impressa; produção de sentidos.

\section{THE NEWS ABOUT THE HEALTH SERVICE CRISIS IN THE NEWSPAPER}

\begin{abstract}
From the perspective of Social Psychology, we agree on the assumption that news media is an important space to propagate information, acting as a co-producer of meanings and of subjectivities in people's everyday lives. Therefore, based on the analysis of newspaper news, published in local newspapers of Campo Grande, MS, and having as their subject health service, more specifically news about the crisis in this kind of service, we critically consider the positioning of hospitals as the privileged locus for health care as well as the vertical forms of negotiation. The rupture with this association and the opening for dialogue conveys a great challenge for the Sistema Única de Sáude - SUS (Brazil's public health care system) so that it can be constituted as a public system, based on universal health care and humanization of health care attention which, under current debate, forms the proposals defended by Collective Health and other fields of knowledge involved in health care, including Psychology.
\end{abstract}

KEYWORDS: Social Psychology; public health; newspapers; production of meaning.

Este artigo alinha-se aos estudos que desenvolvem maneiras de pesquisar no cotidiano e às reflexões feitas no Grupo de Trabalho, Cotidiano e Práticas Sociais, da Associação Nacional de Pós-graduação em Psicologia (ANPPEP). Um dos pontos compartilhados é que o cotidiano constitui-se a partir de re-descrições de situações relacionais que ocorrem no entrelaçamento de materialidades e socialidades (Law, 1999). Evitamos, assim, cair na armadilha de posicionar o cotidiano como expressão de uma realidade, que independe de redes relacionais, constituídas por materialidades e socialidades humanas e não-humanas. Ou seja, cotidiano é constituído por pessoas, conversas, textos escritos, imagens, corporeidades, máquinas, equipamentos, instituições, relações de poder, arquitetura e muitos outros elementos que fazem o nosso social.
A base de reflexão deste artigo advém de uma das maneiras de pesquisar no cotidiano, que envolve a mídia impressa e sua circulação de notícias sobre serviços de saúde. ${ }^{1}$ Como argumentam vários pesquisadores, a mídia é uma prática social que atravessa o cotidiano das pessoas, não apenas veiculando notícias, mas também atuando como co-produtora de sentidos e de subjetividades (Fairclough, 1995; Spink, Medrado, Menegon, Lyra \& Lima, 2001; Thompson, 1995). A mídia, portanto, é uma fonte de pesquisa no cotidiano muito importante, pois desempenha papel relevante (de valor negativo ou positivo) nos processos de produção de sentidos sobre saúde e doença, seja veiculando elementos de vanguarda (Gaskell, Bauer, \& Durant, 1998; Herzlich \& Pierret, 1992), seja reafirmando modelos e práticas tradicionais e discriminatórias (Lyons, 2000; Spink, 2006). 
Quando realizávamos o clipping ${ }^{2}$ de notícias publicadas de janeiro a dezembro de 2005, em cinco jornais de Campo Grande, MS (Correio do Estado, Estado do Mato Grosso do Sul, Folha do Povo, Diário do Pantanal e jornal Primeira Hora), para a pesquisa "Saúde como notícia: Práticas discursivas e produção de sentidos em jornais de Campo Grande, MS' (Menegon, 2006), dois aspectos, que consideramos críticos, nos chamaram a atenção com relação às notícias sobre os serviços de saúde, então publicadas.

Primeiro, porque as notícias indicavam a centralidade do modelo hospitalocêntrico (emergencial, curativo e de reabilitação), reservando um lugar periférico aos serviços de saúde que privilegiam a prevenção de doenças e a promoção da saúde, como é o caso de Unidades Básicas de Saúde (UBS) e de Programas de Saúde da Família (PSF) ou de Centros de Referências, que atuam tanto em níveis de atenção primária como secundária em saúde.

$\mathrm{O}$ segundo aspecto que nos chamou a atenção foram as notícias sobre o período de crise vivenciado pelos serviços de saúde daquela capital, que mostravam o jogo de posicionamentos dos diferentes atores sociais envolvidos e/ou afetados pela situação. Esses dois aspectos nos levaram a refletir acerca do caminho a ser percorrido para que o Sistema Único de Saúde (SUS) se constitua em um sistema público, pautado pelos eixos da integralidade e da humanização no cuidado e na atenção à saúde.

\section{A Saúde no Brasil: Alguns Apontamentos}

O Brasil é um país de extensão continental $\left(8.522 .965 \mathrm{~km}^{2}\right)$, que é caracterizado pela diversidade de saberes e de práticas e por uma população que convive com desigualdades de acesso aos bens e serviços em geral. No caso da saúde, Minayo (1999) discute essas desigualdades problematizando a co-existência de nossos "muitos brasis".

Nesse particular, o Sistema Único de Saúde (SUS), referendado pela Constituição Brasileira de 1988, é uma proposta em prol da diminuição de desigualdades de acesso, agregando noções como universalidade, gratuidade, integralidade, equidade e descentralização das políticas públicas de saúde. Esses princípios vinham sendo debatidos nas décadas anteriores, com a participação da sociedade civil organizada, envolvendo associações, organizações civis, sindicatos e partidos que se alinharam majoritariamente em torno do Movimento da Reforma Sanitária (Luz, 2001).

Entretanto, a viabilização do SUS, ao longo da década de 1990, foi caracterizada por avanços e retrocessos, principalmente no que se refere às contradições dos processos de centralização/descentralização das políticas de saúde, conforme discute Luz (2001). Desde a criação do
SUS, a luta pela descentralização das políticas públicas contou com a participação de setores da sociedade civil, por meio do diálogo com setores institucionais (profissionais, burocratas, gestores). Entretanto, como argumenta Luz, esse diálogo, além da problemática da contradição entre descentralização e concentração dos recursos na esfera federal, varia também de acordo com a cultura político-partidária que formata relações mais ou menos democráticas, em âmbitos municipais e estaduais.

Apesar das dificuldades em garantir a saúde como uma condição para a cidadania, não se negam os esforços e os avanços obtidos em muitas regiões e em diversos segmentos da população. Nesse particular, o balanço de dez anos do SUS, enfocando a década de 1990, mostra avanços e limites da política de saúde no Brasil (Negri, 2002). Esse autor reafirma que um dos problemas crônicos no cuidado com a saúde é a desigualdade regional de prestação de serviços e a distribuição desigual de recursos humanos capacitados.

No debate atual sobre atenção em saúde, na perspectiva da Saúde Coletiva, e no diálogo da Psicologia com o SUS (Menegon \& Coelho, 2006, 2007; Spink \& Matta, 2007), destaca-se a proposta de integralidade, discutida a partir de um leque variado de sentidos, que vem sendo posicionada como estruturante para avançar o SUS (Pinheiro \& Mattos, 2001). Articulando-se à busca de caminhos que levem à integralidade em saúde, a noção de humanização é, também, compreendida como eixo norteador das práticas de atenção e gestão em todas as esferas do SUS, como propõe o HumanizaSUS: Política Nacional de Humanização, desde 2003 (Deslandes, 2004).

Como um princípio do SUS, a integralidade inicialmente referia-se à organicidade do sistema, propondo tanto ações de prevenção como curativas, antes separadas política e administrativamente, nos Ministério da Saúde e da Previdência (Spink \& Matta, 2007). Ou seja, propunha-se a organizar as políticas e serviços do SUS pautando-se pela integralidade das ações de saúde, articulando promoção, prevenção, tratamento e reabilitação.

Entretanto, Mattos (2001) afirma que a produção de outros sentidos sobre integralidade ultrapassou o sentido constitucional inicialmente proposto, passando a focalizar a atenção à pessoa como um todo e não somente sua descrição biológica. Ou seja, o processo saúde-doença é compreendido a partir dos registros social, econômico, político e também psicológico. Reconhece, portanto, o paciente como uma pessoa de direitos, que deve ser atendida a partir de suas necessidades, formatandose, então, discursos e práticas como Medicina Integral, Psicologia Médica e Bioética.

Integralidade, segundo Mattos (2001), deve ser compreendida como dialógica, processual e coletiva, agregando três conjuntos de atuação: os atributos dos profissionais de saúde, que implica em uma boa prática; os 
atributos da organização dos serviços e as respostas governamentais aos problemas de saúde. Para Spink e Matta (2007, p. 47), integralidade “. . . torna-se também uma ética; um valor que pretende construir as políticas, os processos de trabalho e as ações propriamente ditas, a partir da centralidade do usuário e dos sujeitos envolvidos na ação.” Ou seja, integralidade é posicionada como uma micro-política dos processos de atenção à saúde, que bem organizada, traria maior qualidade e efetividade às diferentes ações.

Ampliando ainda mais a noção de integralidade, Cecílio (2001) propõe duas dimensões centradas nas necessidades de saúde. A primeira, "integralidade focalizada", traduz o esforço da equipe multiprofissional, localizada espacialmente nos serviços de saúde (UBS, PSF, Hospital, etc.). Já na segunda dimensão, o autor propõe a integralidade macro, que pressupõe articulações de cada serviço de saúde com uma rede mais complexa de serviços e instituições, não necessariamente do "setor saúde". Neste caso, a mídia (escrita, falada, televisiva) desempenha papel relevante, pois circula saberes e fazeres sobre saúde e doença, que são produzidos em diferentes esferas sociais.

A produção de sentidos sobre os processos de saúde e de adoecimento e de como lidamos com isso, portanto, não se limita aos espaços específicos da rede de saúde, mas está presente em outras relações do cotidiano que, como discute Cecílio (2001), envolvem dimensões micro e macro-sociais.

Como já mencionamos, um outro aspecto importante da busca pela integralidade em saúde é a proposta de humanização. Spink e Matta (2007) argumentam que, apesar das controvérsias acerca da noção de humanização, a sua inserção na agenda de saúde é indicativo de um caminho em direção à superação da histórica associação, que identifica o doente apenas com o modelo anátomofisiológico da Medicina moderna, ignorando que as necessidades das pessoas vão além dos cuidados com a doença e com o corpo. Em síntese, Spink e Matta argumentam que:

Humanizar, no sentido proposto pelo Ministério da Saúde, é mais que reorganizar os espaços sanitários; é reorganizar os processos de trabalho, formar e qualificar trabalhadores, garantir os direitos e a cidadania dos usuários por meio do controle e da participação popular; é instituir práticas fundadas na integralidade. (2007, p. 47).

A noção de humanização em saúde, geralmente designa formas de assistência que valorizam "a qualidade do cuidado do ponto de vista técnico, associadas ao reconhecimento dos direitos do paciente, de sua subjetividade e cultura, além do reconhecimento do profissional" (Deslandes, 2004, p. 8).
A partir da análise de textos oficiais do Ministério da Saúde, a autora discute quatro eixos discursivos sobre humanização:

1. Oposição à violência que habita os serviços, seja diante de "maus tratos", seja "pela dor" do não-atendimento.

2. Oferta de atendimento de qualidade, articulando os avanços tecnológicos com acolhimento.

3. Melhoria das condições de trabalho do profissional, que envolve o cuidado com a sua saúde e as condições de trabalho.

4. Ampliação do processo comunicacional, que é central para inter-relações saudáveis. Neste último caso, o que está em pauta é que o desrespeito ao estatuto ético da palavra engendra arbítrio e violência. Ou seja, quando a palavra fracassa, entram em cena as arbitrariedades.

A partir desses apontamentos sobre integralidade e humanização em saúde observamos que os dois movimentos são estratégias de governamentalidade em saúde, que se caracterizam pela recusa ao autoritarismo hierárquico, às formas reducionistas de compreender os processos de saúde e doença, à falta de diálogo e à objetivação das pessoas. Essas estratégias são formatadas a partir de linguagens sociais advindas de matrizes variadas - setores governamentais, organizações em geral, mídia, comunidades, pessoas, políticas públicas em saúde, etc. , em que se entrelaçam diferentes maneiras de falar sobre os cuidados com a saúde.

Usar a noção de governamentalidade evita reduzirmos os problemas de gestão à esfera do Estado, posicionando-os num campo mais abrangente de governo que perpassa o cotidiano. Para Foucault (1995, p. 291), governamentalidade:

é o conjunto constituído pelas instituições, procedimentos, análises e reflexões, cálculos e táticas que permitem exercer esta forma bastante específica e complexa de poder que tem por alvo a população, por forma principal de saber a economia política e por instrumentos técnicos essenciais os dispositivos de segurança.

Inicialmente direcionada aos estudos sobre biopoderes como força política, a noção de governamentalidade orientava as análises da sociedade disciplinar, tanto no controle de coletivos populacionais como de corpos individuais, no contexto da medicina higienista. Com os avanços da biotecnologia, Rose (2001) amplia essa reflexão propondo formas de poder que denomina de biopolítica e bioeconomia, argumentando que a linguagem é constitutiva de estratégias de governamentalidade, pois não apenas torna os atos de 
governo descritíveis, mas é ela que possibilita sua existência.

Nessa perspectiva, o exercício diário da integralidade e da humanização em saúde repousa também nos sentidos que são atribuídos aos processos de saúde-doença e à atenção em saúde. Os processos de produção de sentidos estão vinculados a matrizes, que são formatadas por materialidades tais como instituições, organizações, pessoas direta e indiretamente envolvidas com o setor saúde, com suas práticas discursivas, além das especificidades da infra-estrutura material.

A proposta de integralidade em saúde como eixo norteador para avançar o SUS, tem possibilitado a produção de novos sentidos para o cuidado com a saúde. Entretanto, a circulação desses sentidos e práticas correspondentes, ainda se limita a determinados espaços da área da saúde. Isso nos leva a refletir sobre o desafio que temos pela frente, pois em nosso tempo longo da história e em nosso tempo vivido (Spink, 2004), construímos sentidos sobre a atenção e o cuidado com a saúde hegemonicamente associados à figura do médico e do hospital, notadamente a partir do século XVIII. Integralidade na atenção à saúde pressupõe interdisciplinaridade e transdisciplinaridade, entretanto, o modelo biomédico, que tem no hospital sua maior expressão, ainda é nuclear no cotidiano da atenção à saúde (Menegon \& Coelho, 2006).

O desafio para a integralidade em saúde ganha contornos mais críticos, quando aspectos nevrálgicos e crônicos são evidenciados pelas crises que eclodem no âmbito dos serviços de saúde em vários estados brasileiros. Esse é o caso da crise noticiada diariamente por jornais de Campo Grande, MS, durante 2005. Como veremos a seguir, a mídia (impressa, falada ou televisiva) é um dos espaços do cotidiano que dá muito mais visibilidade para situações de crise, pois se encaixam na categoria de pauta quente em jornalismo.

\section{A Crise nos Serviços de Saúde no Cotidiano da Mídia Impressa: Um Exemplo de Campo Grande, MS}

As notícias sobre serviços de saúde aqui analisadas foram extraídas do clipping realizado em cinco jornais diários de Campo Grande, MS (Correio do Estado, Estado do Mato Grosso do Sul, Folha do Povo, Diário do Pantanal e jornal Primeira Hora), publicados de janeiro a dezembro de 2005, que foi realizado para a pesquisa "Saúde como notícia: práticas discursivas e produção de sentidos em jornais de Campo Grande, MS" (Menegon, 2006). ${ }^{3}$

Campo Grande, capital do Estado de Mato Grosso do Sul, tem uma população de aproximadamente 800.000 habitantes. Conforme informação da Secretaria Municipal de Saúde Pública (SESAU), a rede municipal de saú- de é constituída por 27 Unidades Básicas de Saúde Urbana, quatro Unidades Básicas de Saúde Rural, dezoito Unidades Básicas de Saúde da Família, nove Centros Regionais - 24 h., dez Centros de Referência e sete Policlínicas Odontológicas (SESAU, 2007). A rede hospitalar conta com 26 serviços, entre serviços públicos e privados, sendo a Santa Casa de Misericórdia um dos maiores complexos hospitalares do Estado de Mato Grosso do Sul.

Conforme mencionamos na introdução, na análise das notícias sobre serviços de saúde, dois aspectos nos levaram a refletir acerca do desafio a ser enfrentado para que o Sistema Único de Saúde (SUS) se constitua em um sistema público, pautado pelos eixos da integralidade e humanização no cuidado e na atenção à saúde.

Em primeiro lugar porque as notícias analisadas redescrevem a hegemonia do modelo hospitalocêntrico, reservando lugar periférico aos serviços de saúde que privilegiam a prevenção de doenças e a promoção da saúde (Unidades Básicas de Saúde, Programas de Saúde da Família, Centros de Referência).

O segundo aspecto está relacionado aos repertórios utilizados nas notícias para relatar a crise instaurada nos serviços de saúde naquele período e o jogo de posicionamentos dos diferentes atores sociais envolvidos e/ou afetados pela crise.

\section{Centralidade do Modelo Hospitalocêntrico na Atenção à Saúde}

Ao considerarmos a visibilidade dada às notícias que envolvem o contexto hospitalar, em comparação às notícias que enfocam outros serviços de saúde, observamos que o hospital (classificado como atenção terciária) ainda é o espaço considerado como o mais importante no cuidado e na atenção à saúde, no cotidiano da mídia impressa. Dentre as 3277 notícias sobre saúde, obtidas por meio de clipping nos cinco jornais anteriormente referidos, 735 (22\%) tinham como foco os serviços de saúde, distribuídos conforme mostra a Tabela 1 .

A Tabela 1 nos mostra que a visibilidade de um tema vai além do número de notícias publicadas. Assim, observamos que as notícias que enfocam o contexto hospitalar representam $84 \%$ das publicações sobre serviços de saúde, das quais $49 \%$ receberam ilustrações e $21 \%$ tiveram chamada de primeira página. No caso das notícias sobre UBS, vale destacar que das 62 notícias, $54 \%$ receberam ilustrações e $24 \%$ tiveram chamada de primeira página.

A análise qualitativa das notícias mostrou que a visibilidade dada às notícias sobre serviços hospitalares, em parte, pode ser explicada pela crise e intervenção realizada na Santa Casa de Misericórdia durante 2005, que repercutiu em todo o sistema de saúde de Campo Grande, MS. Isso explica, também, a relativa visibilidade dada 


\section{Tabela 1}

Distribuição de Notícias sobre Serviços de Saúde, Publicadas em Jornais de Campo Grande, MS, no Período de Janeiro a Dezembro de 2005

\begin{tabular}{ccccc} 
Serviços de & Número de & Notícias com & Chamadas de & $\begin{array}{c}\text { Chamadas de } \\
\text { primeira página } \\
\text { saúde }\end{array}$ \\
notícias & ilustração & primeira página & com ilustração \\
\hline Hospital & 617 & 306 & 135 & 48 \\
UBS & 62 & 34 & 15 & 5 \\
Serviços de & 36 & 2 & 5 & 0 \\
Convênio & & & & 0 \\
PSF & 13 & 6 & 0 & 0 \\
Centro de saúde & 7 & 4 & 0 & 53 \\
Total & 735 & 352 & 155 &
\end{tabular}

Fonte: Menegon (2006).

às UBSs, uma vez que passaram a ser notícia devido ao caos criado pela falta de atendimento hospitalar e ao conseqüente aumento na demanda criada para essas unidades de saúde, conforme discutimos na seqüência.

\section{A Crise da Saúde no Cotidiano das Notícias do Correio do Estado}

Para esta ilustração utilizamos apenas notícias publicadas pelo jornal Correio do Estado (fundado em 1954) que, dos cinco jornais pesquisados, é considerado o mais tradicional e um dos mais respeitados do estado de Mato Grosso do Sul, exercendo liderança nas pesquisas de preferência entre os leitores (História, 2004). Além disso, no clipping realizado foi o jornal que deu mais visibilidade à crise na saúde.

As notícias sobre a crise hospitalar mostram que assuntos ligados à saúde e à doença são mais noticiados quando estão associados a procedimentos complexos e emergenciais. Nessa perspectiva, usando a linguagem jornalística, emergências e complexidades hospitalares são consideradas pauta quente.

As notícias sobre crises hospitalares, com repertórios que evocam situações limite, nos indicam o quanto nosso sistema de saúde ainda está centrado nos grandes complexos hospitalares. Mostram também, a problemática e a contradição presentes nas negociações que en- volvem a equação concentração (de verbas, de decisão e de poder) e descentralização das políticas públicas, situação essa problematizada por Luz (2001).

Para exemplificar essa situação de crise, organizamos uma seqüência de manchetes e títulos sobre o desenrolar da crise instaurada no maior complexo hospitalar do estado, a Santa Casa, e sobre o processo de intervenção. Os itálicos utilizados são destaques analíticos introduzidos por nós.

Campo Grande inicia 2005 em meio a uma grave crise hospitalar e as manchetes de primeira página do Correio do Estado anunciam que o Prefeito Nelsinho Trad toma posse "de olho na crise hospitalar", enquanto o Ministério Público "investiga se omissão provocou morte de ciclista." A Santa Casa, por sua vez, "mantém fechado o acesso principal ao Pronto Socorro, onde a mulher acabou morrendo" e "No Hospital Regional, enquanto aguardam encaminhamento, pacientes ficam espalhados pelos corredores" (Brites, 2 jan. 2005, p. 1A, 6A).

No dia 5 de janeiro de 2005, os leitores são informados de que a "Santa Casa deve sofrer intervenção". O jornal posiciona a Santa Casa como estando em uma unidade de terapia intensiva, destacando como atores sociais o gestor, o poder público e os médicos: "Na UTI: Gestor nomeado pelo poder público, o qual teria apontado irregularidades, foi demitido ontem, provocando reação dos médicos" (Brites, 2005, p. 1A, 7A). 
No dia 6 , as manchetes informam que a crise piorou, e os atores sociais que podem trazer a cura são políticos, o ex-prefeito e o governador do estado: "Piora crise na Santa Casa: André e Orcírio juntam forças para curar Saúde." A medida anunciada é que "A Prefeitura municipal de Campo Grande decretou situação de emergência no Sistema Único de Saúde (SUS) por período de 90 dias" (Brites, 2005, p. 1A, 7A).

Nessa crise, observamos que os sentidos metafóricos de doenças tanto revelam nosso modelo curativo na atenção à saúde como na atenção ao próprio sistema de saúde, que também é tratado de maneira emergencial, conforme afirma esta manchete: "Terceirização e contratos são câncer da Santa Casa". No dia 7 de janeiro de 2005, o jornal noticia um pedido de socorro, "SOS Gestor propôs a revisão de 40 contratos prejudiciais ao hospital. Antes que isso acontecesse, porém, foi sumariamente demitido". "Gestor demitido, Ministro da Saúde acompanha a crise" (Brites, 7 jan. 2005, p. 1A, 7A).

No dia seguinte uma das manchetes do jornal anuncia que o "Ministério segura R\$ 4 milhões da Santa Casa" e ressalta a consequiência disso para os funcionários do complexo hospitalar: "Crise: Medida impediu que o salário de 2,2 mil trabalhadores do hospital previsto para ser pago ontem, fosse liberado" (Brites, 8 jan. 2005, p. 1A, 6A).

No desenrolar da crise, as notícias mostram também o jogo entre descentralização e centralização de decisões e, portanto, de poder, colocando em interação atores sociais da esfera municipal, estadual e federal. No dia 11, o título de uma das notícias afirma que a "Santa Casa terá futuro definido hoje: encontro em Brasília - governador em exercício, prefeito de Campo Grande, o senador Delcídio do Amaral e secretários de saúde reúnem-se com ministro" (Brites, 11 jan. 2005, p. 7A).

Dois dias depois, o Correio do Estado, em seu Editorial "Em estado de coma", discute que "Gestores públicos não chegaram a acordo e adiaram o anúncio oficial das medidas a serem adotadas no hospital". Como resultado do diálogo, ou melhor, da falta de uma cultura do diálogo, o "Ministro manda preparar intervenção na Santa Casa". Nesse dia, ainda, uma das notícias refere-se à população como um ator social que também sofre diretamente as consequiências: "População: Doentes vão ficar sem medicamentos" (Brites, 13 jan. 2005, p. 1A, 2A, 6A).

No dia 16 de janeiro, a população é novamente mencionada. Segundo a notícia, o Secretário da Saúde do município, Luiz Henrique Mandetta, "diz que população deve colaborar para evitar colapso no atendimento" e afirma que para que o problema da saúde pública seja resolvido em Campo Grande, é imprescindível a participação da sociedade no processo: "Precisamos da colaboração da população para que esta nos ajude a sanar a crise." Ainda segundo o jornal, o secretário "falou que pretende estruturar melhor a Rede Básica de Atendimen- to e contar com o apoio do Hospital" (Brites, 13 jan. 2005, p. 1A, 7A).

Nessas notícias, chamamos a atenção para dois pontos: a população é chamada a comparecer como ator que tem um dever a cumprir, ela deve colaborar, ela deve ajudar a sanar a crise; o foco não está na ruptura do direito à saúde e "na dor do não-atendimento", como discute Deslandes (2004).

O outro ponto é a referência à Rede Básica de Atendimento, que frente à crise na rede hospitalar, exibe seus nós de estrangulamento e descaso da política local. Dessa forma, ao entrar na pauta quente de aspectos emergenciais, a rede básica passa a ser notícia. Ou seja, ela ganha visibilidade ao funcionar como um apêndice hospitalar e não devido aos seus vários programas de prevenção e de promoção da saúde que, a despeito dos problemas, são desenvolvidos por equipes de profissionais da saúde, que atuam de maneira interdisciplinar, buscando sensibilizar a população para uma visão ampliada de saúde.

\section{A Rede Básica de Saúde vira Notícia}

No dia 19 de janeiro de 2005, o jornal noticia que "Apesar dos apelos da nova junta administrativa que está frente à Santa Casa, a população continua procurando o hospital para resolver problemas que poderiam ser sanados nos postos de saúde." Nessa notícia observamos que, assim como o jornal dá maior visibilidade às notícias que envolvem procedimentos hospitalares, também para a população em geral, cuidar da saúde está associado ao hospital e à procura de serviços de saúde para sanar doenças já instaladas e cuidados emergenciais. Ou seja, um dos aspectos da lógica da integralidade que inclui a prevenção de doenças e a promoção da saúde, ainda não faz parte do cotidiano da maioria de nossa população (Brites, 19 jan. 2005, p. 7A).

Entramos em fevereiro, com a crise da saúde em manchete, "Crise - Depois da Santa Casa, agora é o Hospital Universitário que não tem remédios nem plantonistas" (Brites, 2 fev. 2005, p. 1A, 7A). No dia seguinte, as notícias descrevem problemas e muitas reclamações referentes ao atendimento da rede básica de saúde do município, pois "Centros de saúde enfrentam falta de médicos e de remédios", e o "Sindicato admite falta de profissionais" (Brites, 3 fev. 2005, p. 6A).

Nas notícias do dia 4 há uma sequiência de manchetes e de fotos que descrevem e ilustram os problemas enfrentados pela população, uma vez que tanto os atendimentos de emergência como os de rotina, são todos encaminhados à rede básica. A população, nas notícias, é sempre posicionada como aquela que sofre, se queixa e reclama. "Herança maldita: com a crise hospitalar, postos ficam superlotados e pacientes são forçados a passar noites 
na fila, que em alguns casos é formada no meio da rua"; "Madrugada retrata caos na saúde: Para tentar atendimento ontem de manhã no posto de saúde do bairro Guanandi, pacientes levaram colchões para enfrentar a temperatura amena da madrugada"; "Pessoas dormem em frente ao centro de saúde para conseguir senha - a longa espera tem início logo nas primeiras horas da noite"; "Homens, mulheres e crianças são obrigados a enfrentar longas filas, em busca de atendimento médico" (Brites, 4 fev. 2005, p. 1A, 6A, 7A).

No dia seguinte, na reportagem "Caos na saúde vai durar 6 meses", ao ser entrevistado, o prefeito reconhece o problema, afirmando que "Os problemas de atendimento nos postos de saúde da capital devem alongarse por mais seis meses", anunciando "que vai adotar medidas emergenciais para tentar melhorar atendimento nos centros regionais". O prefeito ainda admitiu que "pretende deixar as obras para segundo plano para humanizar o atendimento" (Brites, 5 fev. 2005, p. 1A, 7A).

Dois meses depois, a rede básica volta a ser notícia. Em 15 de abril de 2005, os leitores do jornal lêem que o "Caos em postos de saúde deve aumentar", diante do agravamento da crise hospitalar: "Nova crise - suspensão do repasse estadual à Santa Casa e restrição no atendimento no Hospital Regional tendem a piorar o problema de superlotação nos postos". Essa nova crise, entretanto, é significada pelo jornal como algo que já faz parte do cotidiano das pessoas: "Longas filas em frente aos postos de saúde já são rotina durante as madrugadas em Campo Grande: idosos e gestantes obrigados a enfrentar fila quilométrica" (Brites, 15 abr. 2005, p. 1A, 6A).

Essa situação de crise se arrasta ao longo de 2005. Em novembro uma notícia divulga que "Paciente é preso após confusão" em um posto de saúde, exibindo uma foto com a legenda "Vidro da recepção foi quebrado por um paciente irritado" (Brites, 15 nov. 2005, p. 6A).

Em termos de notícias sobre a participação da comunidade e dos usuários, é surpreendente observar o desfecho da crise. A proposta é implantar uma estratégia de governamentalidade que enfatiza a lógica da fiscalização, por meio de um projeto de lei submetido à Câmara Municipal, conforme mostram as manchetes e os títulos das notícias: "Fiscalização: Na próxima terça-feira vai à votação o projeto de lei que obriga a fixação de nomes de plantonistas nas unidades de saúde da capital."; "Pacientes querem listas de médicos em todos os postos"; "Lista permitirá que as pessoas que esperam por atendimento possam fiscalizar a presença dos médicos" (Brites, 25 nov. 2005, p. 12A). Os médicos, por sua vez, reagem: "Médicos querem barrar lista em postos de saúde", explicando que "Entidades discutem hoje projeto que determina afixar nomes dos profissionais de plantão" (28 nov. 2005, p. 6A).
Essa proposta de governamentalidade se afasta de qualquer caminho que nos leve à integralidade e humanização em saúde, pois impede o diálogo e instaura formas autoritárias de relação. É importante observar os repertórios utilizados, pois evocam formas modais imperativas: fiscalizar, obrigar, barrar, determinar.

A notícia que praticamente encerra o ano re-descreve a continuidade de negociações verticais e centralizadoras: "Intervenção na Santa Casa prorrogada por mais 1 ano"; "O prefeito Nelsinho Trad anunciou, ontem, a prorrogação da intervenção, acompanhado pelos secretários estadual e municipal de saúde" (Brites, 21 dez. 2005, p. 1A, 6A).

Como pudemos observar com esta seqüência de manchetes e títulos utilizados para noticiar a crise no sistema de saúde durante 2005, em Campo Grande, MS, os repertórios utilizados nos remetem sempre para práticas emergenciais e espaços de negociação verticalizados e pautados por lógicas autoritárias nas tomadas de decisão. A população aparece como seres passivos que sofrem, quando muito reclamam e brigam. Os desfechos de negociações são de mando e de controle fiscalizador, muito presente na própria lógica da intervenção. Na relação que emerge entre usuários e profissionais médicos, a proposta para o caos da rede básica, que ganha contornos com a crise hospitalar, também é de confronto, pois se apóia no poder fiscalizador.

\section{Considerações Finais}

Conforme mencionamos no início deste artigo, as re-descrições diárias sobre a crise nos serviços de saúde, publicadas pela mídia impressa, nos levaram a refletir sobre o desafio a ser enfrentado para que o Sistema Único de Saúde (SUS) se constitua em um sistema público, pautado pelos eixos da integralidade e humanização no cuidado e na atenção à saúde.

A situação de crise normalmente se constitui na ponta de um iceberg que é formado por problemas que se tornam crônicos devido a gestões pautadas pelo autoritarismo e, portanto, pela falta de diálogo e por ruídos nos processos de comunicação. No caso da saúde, a situação de crise noticiada nos mostra que os pressupostos defendidos para avançar o SUS por meio da integralidade e da humanização em saúde estão ausentes tanto nas micro-relações (que ocorrem nos serviços de saúde) como nas macro-relações, especialmente quando envolve a centralização e a descentralização de recursos e de decisões. Ou seja, as relações são caracterizadas pela falta: falta de participação popular efetiva, de garantia dos direitos à saúde, de condições de trabalho para o profissional, de atendimento de qualidade e pela falta de diálogo e de comunicação efetiva. 
Esta reflexão, entretanto, não se limita aos problemas do cotidiano dos serviços de saúde que foram noticiados e das negociações envolvidas, mas mostra que os sentidos das re-descrições jornalísticas sobre a crise nos remetem a um campo relacional mais amplo da produção de sentidos no cotidiano. Isto é, o tempo longo da história, do qual herdamos sentidos sobre a atenção e o cuidado com a saúde, que giram em torno de dois atores sociais, o médico e a instituição hospitalar que continuam sendo atualizados nos nossos processos de socialização institucional. A força desse sentido está na proposta do Ato Médico.

As re-descrições da crise publicadas pelo Correio do Estado reforçam esse modelo hospitalocêntrico, em detrimento de notícias que dêem visibilidade aos cuidados preventivos e fazeres que promovam a saúde. Essa forma ampliada de cuidar da saúde, conforme mostrou a análise geral das notícias sobre serviços de saúde de Campo Grande, são posicionadas de maneira totalmente periférica pela mídia impressa local.

\section{Notas}

1. Dentre as maneiras de pesquisar no, do e com o cotidiano, desenvolvidas no GT Cotidiano e Práticas Sociais, incluem-se: (a) pesquisas de intervenção, que articulam, recriam e re-descrevem situações do cotidiano, com interações face-a-face (grupos variados, oficinas, conversas do cotidiano); (b) pesquisas no e com o cotidiano dos espaços públicos de convivência, com inter-relação de diferentes socialidades e materialidades (pessoas, conversas, sinalizações visuais, edifícios, ruas, lojas, bancas de jornal, ônibus, carros etc.); (c) pesquisas no cotidiano, que focam a circulação, de repertórios, imagens, sons, cores e outras materialidades em jornais, revistas, televisão, internet, panfletos, out-dors, dentre outros.

2. Clipping é uma terminologia aceita internacionalmente para designar o processo de mapeamento e registro de temas que são publicados na mídia impressa. Existem agências especializadas em realizar esse tipo de pesquisa temática (Spink et al., 2001), todavia é importante observar os objetivos da pesquisa para a sua realização. A opção por clipping próprio visou garantir que a coleta das notícias estivesse integrada aos objetivos, viabilizando tanto a análise quantitativa como preparando o terreno para a fase qualitativa da pesquisa, que envolveu uma análise discursiva multimodal (práticas discursivas e imagens) das notícias.

3. Para a pesquisa "Saúde como notícia: práticas discursivas e produção de sentidos em jornais de Campo Grande, MS", realizamos o clipping de notícias sobre saúde e interrupção da saúde de forma violenta. O tema saúde, utilizado neste artigo, incluiu os seguintes assuntos: avanço de pesquisa; comportamento (estilo de vida, dicas de como se cuidar); desnutrição; doenças em geral (cárdio-vascular, DST-aids, câncer, respiratórias, diabetes e outras); medicamentos; prevenção/promoção; propaganda; saúde reprodutiva; serviços de saúde (UBS, PSF, Hospital, Centros de saúde, Convênios); transmissão de doenças; tratamentos em geral; terapias alternativas; treinamento/ capacitação; vacina (Menegon, 2006).

\section{Referências}

Brites, F. (Ed.). (2005). Correio do Estado. Campo Grande, MS.

Cecílio, L. C. (2001). As necessidades de saúde como conceito estruturante na luta pela integralidade, equidade na atenção em saúde. In R. Pinheiro \& R. A. Mattos (Eds.), Os sentidos da integralidade na atenção e no cuidado à saúde (pp. 39-64). Rio de Janeiro, RJ: Abrasco.

Deslandes, S. F. (2004). Análise do discurso oficial sobre a humanização da assistência hospitalar. Ciência \& Saúde Coleti$v a, 9(1), 7-14$

Fairclough, N. (1995). Media discourse. London: Arnold.

Foucault, M. (1995). A governamentalidade: Curso do Collège de France, 01 de fevereiro de 1978. In M. Foucault. Microfísica do poder. Rio de Janeiro, RJ: Graal.

Gaskell, G., Bauer, M., \& Durant, J. (1998). The representation of biotechnology: Policy, media and public perception. In J. Durant, M. Bauer \& G. Gaskell (Eds.), Biotechnology in the public sphere (pp. 3-8). London: Science Museum.

Herzlich, C., \& Pierret, J. (1992) Uma doença no espaço público. PHYSIS, Revista de Saúde Coletiva, 2(1), 7-35.

História de sonhos e conquistas [Edição especial]. (2004). Correio do Estado, 51(15.436), 25-40.

Law, J. (1999). After ANT: Complexity, naming and topology. In J. Law \& J. Hassard (Eds.), Actor Network Theory and After (pp. 1-14). Oxford, UK: Blackwell.

Luz, M. T. (2001) Políticas de descentralização e cidadania: Novas práticas de saúde no Brasil atual. In R. Pinheiro \& R. A. Mattos (Eds.), Os sentidos da integralidade na atenção e no cuidado à saúde (pp. 39-64). Rio de Janeiro, RJ: Abrasco.

Lyons, A. C. (2000). Examining media representations: Benefits for health psychology. Journal of Health Psychology, 5(3), 267271

Mattos, R. A. (2001). Os sentidos da integralidade: Algumas reflexões acerca de valores que merecem ser defendidos. In R. Pinheiro \& R. A. Mattos (Eds.), Os sentidos da integralidade na atenção e no cuidado à saúde (pp. 39-64). Rio de Janeiro, RJ: Abrasco.

Menegon, V. S. M. (2006). Saúde como notícia: Práticas discursivas e produção de sentidos em jornais de Campo Grande, MS (Relatório de Pesquisa). Campo Grande, MS: Universidade Católica Dom Bosco.

Menegon, V. S. M., \& Coêlho, A. L. E. (2006). A inserção da Psicologia no sistema de saúde pública: Uma prática possível. Barbarói, (24), 177-189.

Menegon, V. S. M., \& Coêlho, A. L. E. (2007). Psicologia e sua inserção no sistema público de saúde: Um painel longitudinal de temas-foco publicados em periódicos brasileiros. In M. J. Spink (Ed.), A Psicologia em diálogo como SUS: Prática profissional e produção acadêmica (pp. 175-205). São Paulo, SP: Casa do Psicólogo.

Minayo, M. C. S. (1999). População brasileira: Um retrato em movimento. In M. C. S. Minayo (Ed.), Os muitos Brasis: Saúde e população na década de 80 (pp. 14-56). São Paulo, SP: Hucitec.

Negri, B. (2002). Introdução: A política de saúde no Brasil nos anos 1990: Avanços e limites. In B. Negri \& A. L. Viana (Eds.), $O$ Sistema Único de Saúde em dez anos de desafio (pp. 15-42). São Paulo, SP: Sobravime.

Pinheiro, R., \& Mattos, R. A. (Eds). (2001). Os sentidos da integralidade na atenção e no cuidado à saúde. Rio de Janeiro, RJ: Abrasco. 
Rose, N. (2001). The politics of life itself. Theory, Culture \& Society, 6(18), 1-30.

Secretaria Municipal de Saúde Pública. (2007). Unidades de Saúde. Campo Grande, MS: Autor. Retirado em 02 abr. 2007, de: http://www.pmcg.ms.gov.br

Spink, M. J. (2004). Linguagem e produção de sentidos no cotidiano: Debates contemporâneos em Psicologia Social. Porto Alegre, RS: Editora da Pontifícia Universidade Católica do Rio Grande do Sul.

Spink, M. J. (2006). O poder das imagens na naturalização das desigualdades: Os crimes no cotidiano da mídia jornalística. In M. J. Spink \& P. Spink (Eds.), Práticas cotidianas e a naturalização da desigualdade: Uma semana de noticias nos jornais (pp. 17-41). São Paulo, SP: Cortez.

Spink, M. J., \& Matta, G. C. (2007). A prática profissional Psi na saúde pública: Configurações históricas e desafios contemporâneos. In M. J. Spink (Ed.), A Psicologia em diálogo com o SUS: Prática profissional e produção acadêmica (pp. 25-51). São Paulo, SP: Casa do Psicólogo.

Spink, M. J., Medrado, B., Menegon, V. M., Lyra, J., \& Lima, H. (2001). A construção da Aids Notícia. Cadernos de Saúde Pública, 17(4), 851-862.

Thompson, J. B. (1995). Ideologia e cultura moderna: Teoria social crítica na era dos meios de comunicação de massa (2. ed.). Petrópolis, RJ: Vozes.

Vera Sonia Mincoff Menegon é docente do Mestrado em Psicologia da Universidade Católica Dom Bosco (UCDB/MS). Endereço para correspondência:

Al. Girassóis, 302, residencial 6, Alphaville, Santana de Parnaíba, SP, 06539-130. mincoff@uol.com.br

\section{Crise dos Serviços de Saúde}

\section{no Cotidiano da Mídia Impressa}

Vera Sonia Mincoff Menegon

Recebido: 17/05/2007

$1^{a}$ revisão: 20/11/2007

Aceite final: 29/11/2007 